\title{
Circadian variation in fibrinolytic activity in patients with variant angina
}

Takenobu Masuda, Hisao Ogawa, Yuji Miyao, Quanjun Yu, Ikuo Misumi, Tomohiro Sakamoto, Hiroto Okubo, Ken Okumura, Hirofumi Yasue

\begin{abstract}
Background-Coronary artery spasm induces activation of the coagulation system. Turnover and maintenance of thrombus depend not only on formation but also on lysis. The relation between coronary spasm and fibrinolytic system has not been elucidated.

Objective-To examine whether there is impairment of or a circadian variation in fibrinolytic activity in patients with variant angina.

Methods-Plasminogen activator inhibitor (PAI) activity and concentrations of tissue plasminogen activator (t-PA) antigen were measured in venous plasma samples taken at 2200,0600 , and 1400 and $24 \mathrm{~h}$ Holter tapes were recorded in 15 patients with variant angina, 12 patients with stable exertional angina, and 12 controls.
\end{abstract}

Results-There were significant circadian variations in PAI activity and $t-P A$ antigen with peak values at 0600 in all three groups. Mean (SEM) PAI activity (IU/ml) at 2200,0600 , and 1400 was $6 \cdot 1$ $(1 \cdot 1), 11.0(1 \cdot 3)$, and $4.4(0.6)$ in the variant angina group; $1.8(0.7), 5.6(1 \cdot 1)$, and $1.2(0 \cdot 3)$ in the stable exertional angina group; and $1.1(0.5), 4.5(0.8)$, and 0.7 $(0 \cdot 3)$ in the control group. Furthermore, both plasma PAI activity and t-PA antigen concentrations were significantly higher in the variant angina group than in the stable exertional angina group and the control group at each sampling time. Conclusions-In patients with variant angina there was a circadian variation in fibrinolytic activity, which was lowest in the early morning, and impaired fibrinolytic activity particularly in the early morning, when attacks of angina occur most frequently.

(Br Heart f 1994;71:156-161)

Variant angina is caused by coronary artery spasm, ${ }^{12}$ which has also been implicated in the pathogenesis of unstable angina and acute myocardial infarction. ${ }^{34}$ Coronary thrombosis also plays an important part in the production of unstable angina or acute myocardial infarction. ${ }^{56}$ The increased tendency to thrombosis can be explained by several mechanisms including increase in platelet aggregation, activation of the coagulation system, ${ }^{89}$ and a defective fibrinolytic system. ${ }^{10}$
Does coronary artery spasm trigger thrombus formation in the coronary artery? We found that coronary artery spasm induced activation of the coagulation system. ${ }^{11-13}$ Turnover of thrombus depends not only on formation but also on lysis, however. The key components of the fibrinolytic system are tissue plasminogen activator (t-PA) and plasminogen activator inhibitor (PAI). t-PA promotes fibrinolysis, ${ }^{14}$ whereas its specific inhibitor, PAI, rapidly inhibits t-PA by complexing with it. ${ }^{15}$ PAI activity, mainly as PAI-1 activity, is a major determinant of overall fibrinolytic activity. ${ }^{1617}$ We showed that PAI activity increased in patients with acute myocardial infarction and unstable angina. ${ }^{1819}$ This confirmed the findings of other investigators. ${ }^{20-22}$ In the present study we measured plasma PAI activity and t-PA antigen to see whether there is impairment or a circadian variation in the fibrinolytic system in patients with variant angina. We also examined the relation between the circadian variation in the fibrinolytic system and ischaemic attacks.

\section{Patients and methods}

\section{PATIENTS}

We studied 39 patients who underwent diagnostic cardiac catheterisation ( 32 men and seven women; mean (SEM) age $60 \cdot 4(1 \cdot 1)$, range 48-73). They were divided into three groups: the variant angina group, the stable exertional angina group and controls.

The variant angina group consisted of 15 consecutive patients with variant angina. All patients had attacks of chest pain at rest, usually occurring from midnight to early morning and associated with reversible ST segment elevation on electrocardiogram (ECG). We excluded patients with ST changes lasting more than 30 minutes, with new $Q$ waves, or with raised plasma concentrations of creatine kinase or creatine kinase MB.

The stable exertional angina group consisted of 12 patients who had typical chest pain on exertion associated with horizontal or downsloping ST segment depression of greater than $1.0 \mathrm{~mm}$ at $80 \mathrm{~ms}$ after the J point. All patients in this group had experienced angina attacks at least once a month before the study. None had episodes of rest angina or showed ischaemia during a hyperventilation test.

The control group consisted of 12 patients with atypical chest pain not accompanied 
Table 1 Characteristics of the study groups (mean (SEM))

\begin{tabular}{|c|c|c|c|}
\hline Characteristic & $\begin{array}{l}\text { Variant } \\
\text { angina }\end{array}$ & $\begin{array}{l}\text { Stable } \\
\text { exertional } \\
\text { angina }\end{array}$ & Controls \\
\hline $\begin{array}{l}\text { No. of patients } \\
\text { Age (yr): }\end{array}$ & 15 & 12 & 12 \\
\hline Mean (SEM) & $60 \cdot 0(1 \cdot 6)$ & $60 \cdot 8(2 \cdot 2)$ & $60 \cdot 7(2 \cdot 0)$ \\
\hline Range & $48-69$ & $51-72$ & $49-73$ \\
\hline Male/female & $13 / 2$ & $10 / 2$ & $9 / 3$ \\
\hline Previous myocardial infarction (n) & 1 & 2 & 0 \\
\hline Blood pressure $\geqslant 150 / 90 \mathrm{~mm} \mathrm{Hg}$ (n) & 7 & 5 & 6 \\
\hline Smokers (n) & 12 & 9 & 9 \\
\hline Diabetes mellitus (n) & 3 & 2 & 1 \\
\hline Obesity (n) & 2 & 1 & i \\
\hline $\begin{array}{l}\text { Serum cholesterol (mg/dl) } \\
\text { Serum triglyceride (mg/dl) }\end{array}$ & $\begin{array}{l}200(8) \\
176(22)\end{array}$ & $\begin{array}{l}217(10) \\
143(14)\end{array}$ & $194(10)$ \\
\hline \\
\hline $\begin{array}{l}\text { organic stenosis } \geqslant 75 \% \text { stenosis (m): } \\
\text { 0-vessel }\end{array}$ & $12^{\star}$ & 0 & 12 \\
\hline 1-vessel & 1 & 5 & 0 \\
\hline 2-vessel & 2 & 6 & 0 \\
\hline 3-vessel & 0 & 1 & 0 \\
\hline \multicolumn{4}{|l|}{ Coronary artery spasm $(n)$ : } \\
\hline Single vessel spasm & $7^{\star}$ & 0 & 0 \\
\hline Multivessel spasm & $8^{\star}$ & 0 & 0 \\
\hline Ejection fraction $<50 \%(n)$ & 1 & 0 & 0 \\
\hline \multicolumn{4}{|l|}{ Medication used (n): } \\
\hline$\beta$ Blockers & 0 & 1 & 0 \\
\hline Long acting nitrates & 1 & 3 & 0 \\
\hline Calcium antagonists & 3 & 3 & 0 \\
\hline Aspirin & 1 & 1 & 0 \\
\hline
\end{tabular}

with electrocardiographic changes of ischaemia on a treadmill exercise test and hyperventilation test.

The stable exertional angina group and the controls were selected from patients presenting for elective cardiac catheterisation during the same period and matched for age, sex, and other clinical variables with the group with variant angina. Table 1 shows the clinical characteristics of the three groups.

None of the patients was treated with thrombolytic agents such as urokinase, streptokinase, or alteplase, or anticoagulants or steroids. None of them had thromboembolism, collagen disease, disseminated intravascular coagulation, advanced liver disease, renal failure, malignant disease, septicaemia or other inflammatory disease. None of them had a prosthetic heart valve or a pacemaker.

\section{STUDY PROTOCOL}

Blood samples were obtained from patients every $8 \mathrm{~h}$ at 2200, 0600, and 1400. All patients underwent $24 \mathrm{~h}$ Holter recording with a Del Mar Avionics (Irvine, California) model 447 two-channel recorder for at least 24 hours on the day of blood sampling. Furthermore, in seven patients with variant angina we obtained additional blood samples before (at 0600 or 1400) and within 15 minutes after attacks that occurred between 0600 and 0700 or between 1400 and 1500 . An ischaemic attack was defined as more than $2.0 \mathrm{~mm}$ ST segment elevation or more than $1.0 \mathrm{~mm}$ horizontal or downsloping ST segment depression $80 \mathrm{~ms}$ after the J point that lasted for at least a minute.

The study protocol accorded with the guidelines of the ethics committee at our institution. Informed consent was obtained from each patient.
BLOOD SAMPLING

After admission blood samples were taken by venepuncture by specially trained physicians (TM and YM) who were evaluated by quality control procedures before and during the study.

The first $3 \mathrm{ml}$ of blood was discarded, then $4.5 \mathrm{ml}$ of blood was drawn directly into glass tube containing $0.5 \mathrm{ml}$ of $3.8 \%$ buffered citrate solution and processed immediately. Samples were centrifuged immediately at $2000 \times g$ for 15 minutes at $4^{\circ} \mathrm{C}$ to obtain platelet poor plasma and the plasma was stored at $-80^{\circ} \mathrm{C}$.

\section{DETERMINATION OF T-PA ANTIGEN}

\section{CONCENTRATION AND PAI ACTIVITY}

We measured t-PA antigen by an enzyme linked immunosorbent assay (ELISA) using the reagent kit ASSERACHROM t-PA from Diagnostica Stago (Franconville, France). ${ }^{23}$ Results were expressed as $\mathrm{ng} / \mathrm{ml}$. Intra-assay and inter-assay coefficients of variation were $2.4 \%$ and $4.7 \%$ respectively. The normal value for t-PA antigen at 0600 in our laboratory $(n=33)$ was $5 \cdot 6(0 \cdot 3) \quad($ mean $($ SEM $))$ $\mathrm{ng} / \mathrm{ml}$.

We measured PAI activity by a chromogenic substrate assay using a reagent kit (Spectrolyse/PL) from Biopool (Umeå, Sweden). ${ }^{16}$ Results were expressed as $\mathrm{IU} / \mathrm{ml}$. Intra-assay and inter-assay coefficients of variation were $9.4 \%$ and $11.4 \%$ respectively. The normal value for PAI activity at 0600 in our laboratory $(n=33)$ was $5 \cdot 2(0 \cdot 5)$ (mean(SEM)) IU/ml.

\section{STATISTICAL ANALYSIS}

We used one way analysis of variance to compare plasma t-PA antigen concentration and PAI activity at each sampling time, age, serum cholesterol, and serum triglyceride in the three groups. When the result was significant Duncan's multiple range test was performed. We evaluated significant differences in plasma t-PA antigen and PAI activity with time by analysis of variance. When this was significant we used Bonferroni's criterion for paired comparisons. Changes in plasma PAI activity and $\mathrm{t}-\mathrm{PA}$ antigen concentrations before and after attacks were estimated by a paired $t$ test. The clinical characteristics of the three groups in table 1, except age, serum cholesterol, and serum triglyceride, were compared by a $\chi^{2}$ test. The distribution of the number of attacks occurring in the 8 hour intervals was first tested for differences among the three periods by a $\chi^{2}$ test for goodness of fit. If this test showed significant differences, the period with the highest frequency was compared with the average of the other two periods combined. $p$ Values of $<0.05$ were regarded as statistically significant. Data were expressed as mean (SEM).

\section{Results}

CHARACTERISTICS OF THE STUDY GROUPS

Table 1 shows the clinical characteristics of patients with variant angina, of patients with 


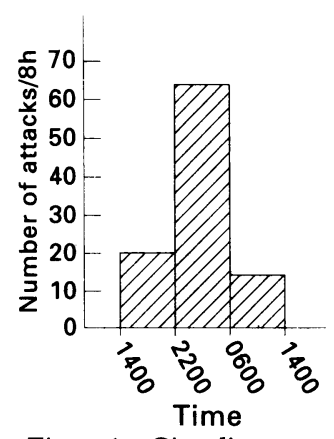

Figure 1 Circadian distribution of number of ischaemic attacks in patients with variant angina. There was a significant circadian variation in the frequency of the attacks, which reached a peak between 2200 and 0600 $(p<0.01)$. stable exertional angina, and of controls. Plasma PAI activity and t-PA antigen concentrations are known to be influenced by age, sex, serum triglyceride, diabetes mellitus, hypertension, smoking, and obesity. ${ }^{24-28}$ There were no significant differences in these variables among the three study groups. One patient with variant angina and two patients with stable exertional angina had a history of previous myocardial infarction at least 3 months before the study. In principle, all drugs except glyceryl trinitrate were stopped for at least 3 days before the study day. However, three patients with variant angina had severe attacks and were treated with antianginal drugs on the study day-two of them with calcium antagonist and the other with calcium antagonist and long acting nitrate. Three of the 12 patients with stable exertional angina were receiving medication on the study day-calcium antagonist and long acting nitrate in two and calcium antagonist, long acting nitrate, $\beta$ blocker, and aspirin in the third-because they had the past histories of unstable angina and multivessel disease with severe organic stenosis. None of the controls was receiving medication on the study day. There was no difference in the number of patients receiving drugs $(\beta$ blockers, long acting nitrates, calcium antagonists, aspirin and other drugs) between the variant angina group and the stable angina group.

\section{CORONARY ARTERIOGRAPHY}

Cardiac catheterisation including coronary arteriography was performed in all patients within a week after the study. Coronary arteriography showed coronary artery spasm during the attacks of angina provoked by intracoronary injection of acetylcholine ${ }^{29}$ in 14 patients with variant angina during attack. In one patient intracoronary acetylcholine was not injected because he had severe organic coronary stenosis.

Three patients with variant angina had significant organic stenosis. Two had two vessel disease and the other had single vessel disease.

All the patients with stable exertional angina had major coronary arteries with $\geqslant 90 \%$ diameter stenosis. None of the controls had significant organic stenosis in their coronary arteries and no coronary artery spasm was induced by intracoronary injection of acetylcholine in any of control subjects. Table 1 shows the number of diseased vessel in the three groups.

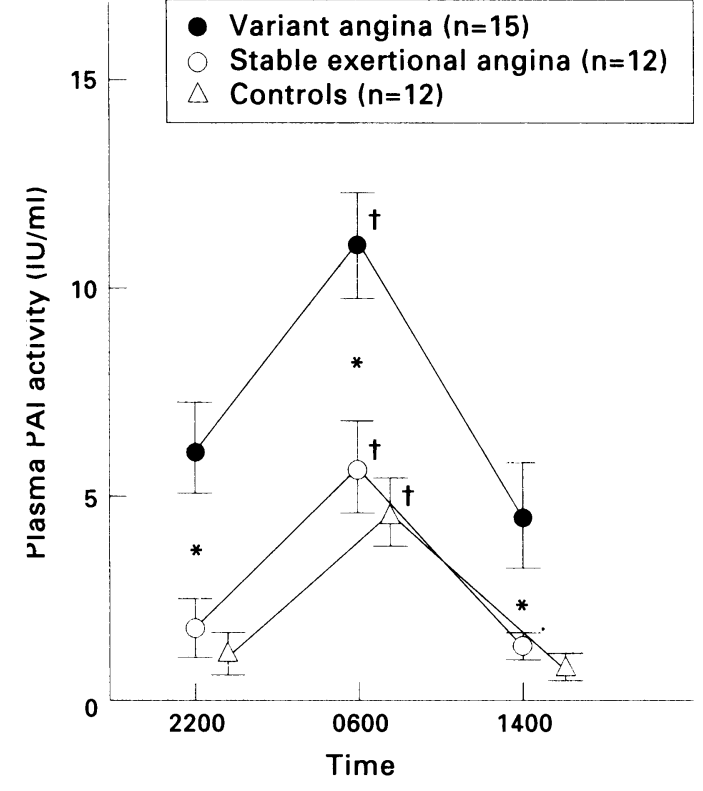

${ }^{*} p<0.01 v$ stable exertional angina and controls

$t p<0.01 \vee 2200$ and 1400

Figure 2 Plasma PAI activity in patients with variant angina, with stable exertional angina, and in controls. Data are expressed as mean (SEM). Plasma PAI activity showed a significant circadian variation with a peak at 0600 in patients with variant angina, in those with stable exertional angina, and in controls $(p<0.01)$. $P A I$ activity was significantly higher in patients with variant angina than in those with stable exertional angina and in controls at each sampling time $(p<0.01)$.

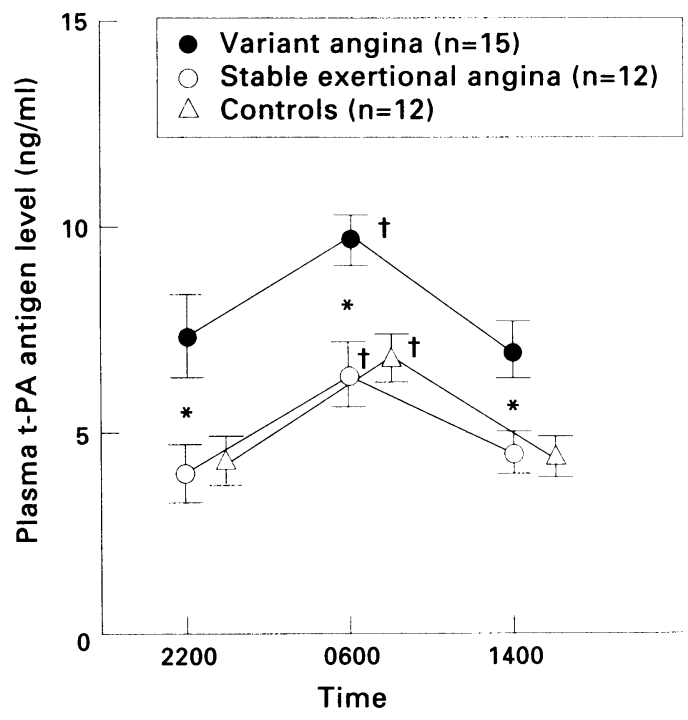

${ }^{*} p<0.01 v$ stable exertional angina group and controls tp $<0.01 \vee 2200$ and 1400

Figure $3 t-P A$ antigen concentration in patients with variant angina, in patients with stable exertional angina, and in controls. Data are expressed as mean (SEM). Plasma t-PA antigen concentrations showed a significant circadian variation with a peak at 0600 in patients with variant angina, in those with stable exertional angina, and in controls $(p<0 \cdot 01)$. $t-P A$ concentrations were significantly higher in patients with variant angina than in those with stable exertional angina and controls at each sampling time $(p<0.01)$.
Stable exertio

t-PA antigen $(\mathrm{ng} / \mathrm{ml})$

Stable exertional angina

Controls

${ }^{\star} \mathrm{p}<0.01 v$ stable exertional angina and controls; $\nmid \mathrm{p}<0.01 v 2200$ and 1400 .
$4 \cdot 4(0 \cdot 6)^{\star}$

$1.2(0.3)$
$0.7(0.3)$

$1.1(0.5)$

$7 \cdot 0(0.6)$

$4.4(0.5)$ 
Figure 4 Line graph showing plasma $P A I$ activity $(A)$ and $t-P A$ antigen concentrations $(B)$ before and after eight ischaemic attacks in seven patients with variant angina. Plasma PAI activity and $t-P A$ antigen were significantly higher after the attacks than before the attacks $(p<0.05)$.
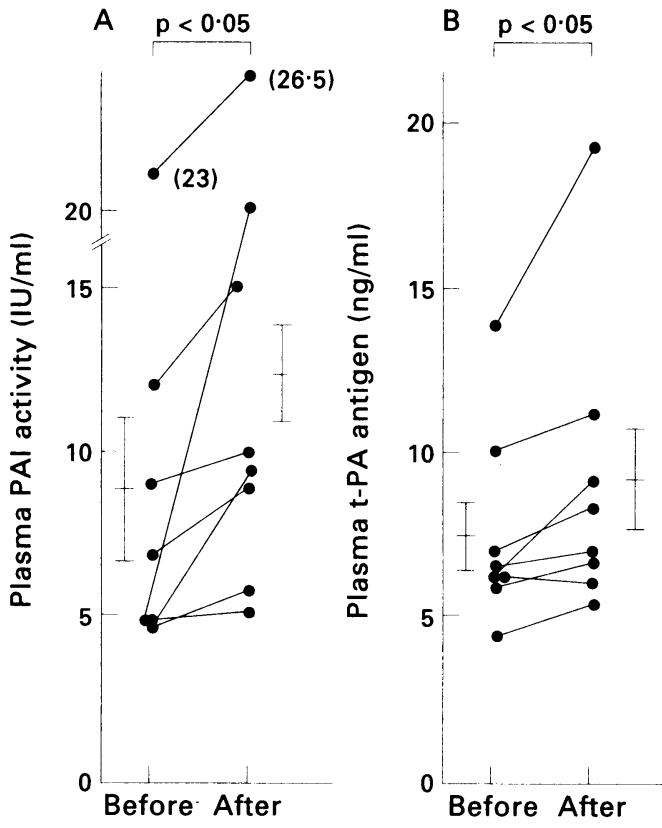

RESULTS OF 24 HOUR HOLTER ECG

Thirteen patients with variant angina had between one and 14 ischaemic attacks and 96 of these episodes occurred on the study day. Sixty four $(67 \%), 12(13 \%)$, and $20(20 \%)$ of 96 attacks occurred between 2200 and 0600 , between 0600 and 1400 , and between 1400 and 0600 , respectively. There was a significant circadian variation in the frequency of attacks with the peak incidence occurring from 2200 to 0600 ( $p<0.01$ ) (fig 1). None of the patients with stable exertional angina had attacks during the study.

PLASMA PAI ACTIVITY

Table 2 and fig 2 show mean plasma PAI activity (IU/ml) in the three study groups at 2200, 0600, and 1400. Plasma PAI activity showed considerable circadian variation with a peak level at 0600 in all of the three study groups $(p<0.01)$ and was significantly higher at all of sampling times in the variant angina group than in the stable exertional angina group and in the controls, particularly at $0600(p<0.01)$ (fig 2). There were no significant differences in plasma PAI activity at any of the sampling times between the stable exertional angina group and the control group (fig 2).

\section{PLASMA T-PA ANTIGEN CONCENTRATION}

Table 2 and fig 3 show the mean plasma t-PA antigen concentrations $(\mathrm{ng} / \mathrm{ml})$ in the three study groups at 2200,0600 , and 1400 . The plasma t-PA antigen concentrations showed the same significant circadian variation, with a peak at 0600 , as plasma PAI activity in all of the three study groups $(p<0.01)$ and the concentration was significantly higher at all sampling times in the variant angina group than in the stable exertional angina group and the controls, particularly at 0600 ( $p<0.01$, fig 3 ). There were no significant differences in plasma t-PA antigen concentration at any of the sampling times between the stable exertional angina group and control group (fig 3).

\section{PLASMA PAI ACTIVITY AND T-PA ANTIGEN} CONCENTRATIONS AFTER ISCHAEMIC ATTACKS In seven patients we took blood samples before and within 15 minutes after eight ischaemic attacks in addition to routine sampling every eight hours. Plasma PAI activity and $\mathrm{t}-\mathrm{PA}$ antigen concentration were significantly higher after the attacks $(8 \cdot 8(2 \cdot 2) v$ $12.3(2 \cdot 5) \mathrm{IU} / \mathrm{ml}, \mathrm{p}<0.05$ for PAI activity and $7.4(1.0) v 9.1(1.6) \mathrm{ng} / \mathrm{ml}, \mathrm{p}<0.05$ for t-PA antigen) (fig 4).

\section{Discussion}

Coronary spasm is important in the production of acute myocardial infarction in some patients. ${ }^{34}$ None the less it is not clear whether coronary spasm causes intracoronary thrombus formation. We found that plasma fibrinopeptide A (FPA), a specific marker of thrombin generation and activation of coagulation system, ${ }^{30}$ was increased during or after episodes of angina in patients with coronary spastic angina. ${ }^{112} \mathrm{We}$ also showed that a circadian variation in plasma FPA concentrations paralleled the episodes of angina in patients with variant angina and showed that this circadian variation resulted from the attacks. ${ }^{11}$ Furthermore, we showed that FPA was released into the coronary circulation after coronary spasm. ${ }^{13}$ These findings indicate that coronary spasm activates the coagulation system and may initiate intracoronary thrombus formation. However, the maintenance of thrombus depends not only on its formation but also on its lysis. We and others have reported an increase in plasma PAI activity in patients with acute myocardial infarction and unstable angina. ${ }^{18-22}$ Others have reported circadian variation in plasma PAI in these patients. ${ }^{31}$

Our study showed that there were significant circadian variations in plasma PAI activity and t-PA antigen, with a peak level at 0600 , in patients with variant angina, in those with stable exertional angina, and in controls. We also showed that the circadian variation in these variables in patients with variant angina paralleled the ischaemic attacks. Furthermore, the present study showed that both plasma PAI activity and t-PA antigen concentrations were significantly higher at each sampling time in patients with variant angina than in those with stable exertional angina and in controls. These results indicate circadian variation in fibrinolytic activity in patients with variant angina with the lowest level in the morning when the incidence of ischaemia is highest. The results also suggest that fibrinolytic activity is impaired in these patients, particularly in the early morning when angina attacks are most common.

Thus the present study together with our previous studies ${ }^{11-13}$ suggests that coronary spasm may trigger thrombus formation in 
coronary arteries and that the reduction of fibrinolytic activity may slow the removal of thrombus, ultimately leading to acute myocardial infarction in some patients, particularly in the early morning.

The present study cannot clearly show whether the increase in plasma PAI activity and t-PA antigen concentration is the result or the cause of attacks in patients with variant angina. We showed that plasma PAI activity and t-PA antigen concentration increased significantly after episodes of angina in patients with variant angina in this study, which indicates that the increase in plasma PAI activity and t-PA antigen concentration may be the result of the ischaemic attacks.

In vivo PAI inhibits t-PA activity by complexing with it, ${ }^{14}$ and PAI activity represents free PAI not combined with t-PA antigen and thus antifibrinolytic activity. In the present study t-PA antigen was also increased in patients with variant angina. However, because PAI activity was increased in these patients the degree of increase in t-PA antigen was less in relation to that of PAI.

The mechanism responsible for the increase in PAI and t-PA in patients with variant angina is still unknown. There are reports that stimulation of human endothelial cells and hepatic cells by thrombin resulted in the release of both t-PA and PAI-1.3233 Our previous studies in patients with variant angina showed that plasma FPA concentrations were increased and showed a circadian pattern with a peak in the early morning. In the present study we found circadian variation of plasma PAI activity and t-PA antigen in patients with variant angina that resembled that of plasma FPA. Thus the increase in plasma PAI activity and t-PA antigen in these patients may result from the reaction of thrombin on endothelial cells and/or hepatic cells. It has been reported that thrombin activates platelets, ${ }^{34}$ which contain PAI- ${ }^{35}$ and transforming growth factor beta (TGF- $\beta$ ) and epidermal growth factor (EGF). These growth factors stimulate synthesis of PAI-1 in human hepatic cells and endothelial cells in culture and in vivo. ${ }^{33}$ 36-38 Thus PAI- 1 may be released from activated platelets or TGF- $\beta$ and EGF may be released from activated platelets to stimulate synthesis of PAI-1. PAI is also an acute phase reactant. ${ }^{15}$ The increase in plasma PAI activity may in part reflect the acute phase reaction.

We found that the plasma PAI activity in patients with variant angina showed a dynamic circadian variation with a peak in the early morning which paralleled the distribution of attacks. PAI activity at each sampling time was higher in patients with variant angina than in patients with stable exertional angina or controls, particularly in the early morning. This antifibrinolytic tendency in the early morning may be an important factor in the higher incidence of cardiovascular events in the morning. ${ }^{39}$

This study was supported in part by a grant in aid for Scientific Research from the Ministry of Education
(B03454257, C05670621) and a research grant from the Smoking Research Foundation, Tokyo, Japan.

1 Oliva PB, Potts DE, Pluss RG. Coronary arterial spasm in Prinzmetal angina. Documentation by coronary angiography. $N$ Engl $\mathcal{F}$ Med 1973;288:745-51.

2 Yasue H, Touyama M, Kato H, Tanaka S, Akiyama F Prinzmetal's variant form of angina pectoris as a manifestation of alpha-adrenergic receptor-mediated coronary artery spasm. Documentation by coronary nary artery spasm. Documentation by

3 Oliva PB, Breckinridge JC. Arteriographic evidence of coronary arterial spasm in acute myocardial infarction. Circulation 1977;56:366-74

4 Maseri A, L'Abbate A, Baroldi G, Chierchia A, Marzilli $\mathrm{M}$, Ballestra $\mathrm{AM}$, et al. Coronary vasospasm as a possible cause of myocardial infarction: A conclusion derived from the study of "preinfarction" angina. N Engl $₹ \mathrm{Med}$ 1978;299:1271-7.

5 Sherman CT, Litvack F, Grundfest W, Lee M, Hickey A, Chaux A, et al. Coronary angioscopy in patients with unstable angina pectoris. $N$ Engl $f$ Med 1986;315

6 Roberts WC, Jones AA. Quantification of coronary arterial narrowing at necropsy in acute transmural infarction: Analysis and comparison of findings in 27 patients and 22 controls. Circulation 1980;61:786-90.

7 Fitzgerald DJ, Roy L, Catella F, Fitzgerald GA. Platelet activation in unstable coronary disease. $N \mathrm{Engl} F \mathrm{Med}$ 1986;315:983-8.

8 Eisenberg PR, Sherman LA, Schectman K, Perez J, Sobel BE, Jaffe AS. Fibrinopeptide A: A marker of coronary thrombosis. Circulation 1985;71:912-8.

9 Théroux P, Latour JG, Léger-Gauthier C, Lara JD. Fibrinopeptide $A$ and platelet factor levels in unstable angina pectoris. Circulation 1987;75:156-62.

10 Nilsson IM, Ljungner $H$, Tengbon $L$. Two different mechanisms in patients with venous thrombosis and defective fibrinolysis: low concentration of plasminogen activator or increased concentration of plasminogen activator inhibitor. $\mathrm{Br} \mathrm{Med} \mathcal{F}$ 1985;290:1453-5.

11 Ogawa H, Yasue H, Oshima S, Okumura K, Matsuyama $\mathrm{K}$, Obata $\mathrm{K}$. Circadian variation of plasma fibrinopeptide A level in patients with variant angina. Circulation tide A level in patien

12 Oshima S, Ogawa H, Yasue H, Okumura K, Matsuyama K, Miyagi H. Increased plasma fibrinopeptide A levels during attacks induced by hyperventilation in patients with coronary vasospastic angina. I Am Coll Cardiol 1989;14:150-4.

13 Oshima S, Yasue H, Ogawa H, Okumura K, Matsuyama $\mathrm{K}$. Fibrinopeptide $A$ is released into the coronary circulation after coronary spasm. Circulation 1990;82:2222-5.

14 Zamarron C, Lijnen HR, Collen D. Kinetics of the activation of plasminogen by natural and recombinant tissue-plasminogen activator. $\mathcal{F}$ Biol Chem 1984;259: 2080-3.

15 Sprengers ED, Kluft C. Plasminogen activator inhibitors. Blood 1987;69:381-7.

16 Eriksson E, Rånby $M$, Gyzander E, Risberg B. Determination of plasminogen activator inhibitor in plasma using t-PA and a chromogenic single-point polyD-lysine stimulated assay. Thromb Res 1988;50:91-101.

17 Urano T, Sakakibara K, Andrzej R, Urano S, Takada Y, Takada A. Relationships between euglobulin clot lysis time and the plasma levels of tissue plasminogen actitime and the plasma levels of tissue plasminogen acti-
vator and plasminogen activator inhibitor 1. Thromb vator and plasminogen
Haemost 1990;63:82-6.

18 Masuda T, Yasue H, Ogawa H, Misumi I, Sakamoto T, Okubo $\mathrm{H}$, et al. Plasma plasminogen activator inhibitor activity and tissue plasminogen activator levels in patients with unstable angina and those with coronary spastic angina. Am Heart f 1992;124:314-9.

19 Sakamoto T, Yasue H, Ogawa H, Misumi I, Masuda T. Association of patency of the infarct-related coronary artery with plasma levels of plasminogen activator inhibitor activity in acute myocardial infarction. $\mathrm{Am} \mathcal{F}$ Cardiol 1992;70:271-6.

20 Hamsten A, Wiman B, De Faire U, Blomback $M$. Increased plasma levels of a rapid inhibitor of tissue plasminogen activator in young survivors of myocardial infarction. $N$ Engl f Med 1985;313:1557-63.

21 Lucore CL, Sobel BE. Interactions of tissue-type plasminogen activator with plasma inhibitors and their

22 Zalewski A, Shi Y, Nardone D, Bravette B, Weinstock P, Fischman D, et al. Evidence for reduced fibrinolytic Fischman D, et al. Evidence for reduced fibrinolytic
activity in unstable angina at rest: clinical, biochemical, activity in unstable angina at rest: clinical, biochemical,
and angiographic correlates. Circulation 1991;83: and angiogr $1685-91$.

23 Amiral J, Plassart V, Grosley M, Mimilla F, Contant G, Guyader AM. Measurement of $t-P A$ and $t-P A-P A I-1$ complexes by ELISA, using monoclonal antibodies: Clinical relevance. Thromb Res 1988;Suppl VIII: 99-113.

24 Mehta J, Mehta P, Lawson D, Saldeen T. Plasma tissue plasminogen activator inhibitor levels in coronary artery disease: Correlation with age and serum triglyceride concentrations. F Am Coll Cardiol 1987;9:263-8.

25 Olofsson BO, Dahlen G, Nilsson TK. Evidence for increased levels of plasminogen activator inhibitor and tissue plasminogen activator in plasma of patients with 
angiographically verified coronary artery disease. Eur Heart of 1989;10:77-82.

26 Takada $Y$, Takada A Plasma levels of $t-P A$, free PAI- 1 and complex of $t-P A$ with PAI- 1 in human males and females at various ages. Thromb Res 1989;55:601-9.

27 Landin K, Tengborn L, Smith U. Elevated fibrinogen and plasminogen activator inhibitor (PAI-1) in hypertension are related to metabolic risk factor for cardiovascular disease. F Intern Med 1990;227:273-8.

28 Juhan-Vague I, Vague P, Alessi MC, Badier C, Valadier J, Aillaud MF, et al. Relationship between plasma insulin, body mass index and plasminogen activator inhibitor-1. Diabete Metab 1987;13:331-6.

29 Yasue $H$, Horio $Y$, Nakamura $N$, Fujii $H$, Imoto $N$, Sonoda $R$, et al. Induction of coronary artery spasm by acetylcholine in patients with variant angina: Possible role of the parasympathetic nervous system in the role of the parasympathetic nervous system in the pathogenesis of

30 Nossel HI, Yudelman I, Canfield RE, Butler UP Jr, Spanondis K, Wilner GD, et al. Measurement of fibrinopeptide $\mathrm{A}$ in human blood. $f$ Clin Invest 1974; 54:43-53.

31 Angelton P, Chandler WL, Schmer G. Diurnal variation of tissue plasminogen activator and its rapid inhibitor (PAI-1). Circulation 1989;79:101-6.

32 Gelehrter TD, Sznycer-Laszuk R. Thrombin induction of plasminogen activator-inhibitor in cultured human endothelial cells. 7 Clin Invest 1986;77:165-9.

33 William EH, Fujii S, Sobel BE. Synergistic induction of plasminogen activator inhibitor type-1 in HEPG2 cells plasminogen activator inhibitor type-1 in HEPG2 cells 1992;79:75-81.

34 Harmon JT, Jamieson GA. Platelet activation by alphathrombin is a receptor-mediated event. Ann NY Acad Sci 1986;485:387-95.

35 Erickson LA, Ginsberg MH, Loskutoff DJ. Detection and partial characterization of an inhibitor of plasminogen activator in human platelets. F Clin Invest 1984;74: 1465-72.

36 Fujii S, William EH, Sobel BE. Mechanisms contributing to increased synthesis of plasminogen activator inhibitor type 1 in endothelial cells by constituents of platelets and their implications for thrombolysis. Circulation and their implicat

37 Fujii S, Lucore CL, Hopkins WE, Billadello J, Sobel BE. Potential attenuation of fibrinolysis by growth factors released from platelets and their pharmacologic implications. Am r Cardiol 1989;63:1505-11.

38 Fujii $S$, Sobel BE. Induction of plasminogen activator inhibitor by products released from platelets. Circulation 1990;82:1485-93.

39 Muller JE, Stone PH, Turi ZG, Rutherford JD, Czeisler CA, Parker C, et al. MIIIS Study Group. Circadian variation in the frequency of onset of acute myocardial infarction. N Engl F Med 1985;313:1315-22. 